\title{
Predictive Value of Clinical and Laboratory Parameters for Overt Bone Marrow Metastasis in Patients with Solid Malignancy
}

\author{
Kalman Filanovsky ${ }^{1 *}$, Edit Feldberg' ${ }^{2}$, Edward B. Miller ${ }^{3}$, Lev Shvidel ${ }^{1}$ \\ ${ }^{1}$ Department of Hematology, Kaplan Medical Center, Hadassah and Hebrew University Medical School, Jerusalem, Israel \\ ${ }^{2}$ Department of Pathology, Kaplan Medical Center, Hadassah and Hebrew University Medical School, Jerusalem, Israel \\ ${ }^{3}$ Department of Internal Medicine D, Kaplan Medical Center, Hadassah and Hebrew University Medical School, Jerusalem, Israel \\ Email: ^kalmanph@clalit.org.il
}

How to cite this paper: Filanovsky, K., Feldberg, E., Miller, E.B. and Shvidel, L. (2017) Predictive Value of Clinical and Laboratory Parameters for Overt Bone Marrow Metastasis in Patients with Solid Malignancy. Journal of Cancer Therapy, 8, 773-784.

https://doi.org/10.4236/jct.2017.88067

Received: July 2, 2017

Accepted: August 7, 2017

Published: August 10, 2017

Copyright $\odot 2017$ by authors and Scientific Research Publishing Inc. This work is licensed under the Creative Commons Attribution International License (CC BY 4.0).

http://creativecommons.org/licenses/by/4.0/

\begin{abstract}
Bone marrow (BM) metastases are known to worsen the outcome in patients with malignancies and alter the choice of the treatment regimen. In an attempt to identify routine parameters for the prediction of BM metastasis we evaluated the clinical and laboratory data of 103 patients with metastatic solid tumors. We also assessed which of these factors appeared to influence survival. Three laboratory abnormalities were found to be predictive of metastasis on BM biopsy: thrombocytopenia $<50 \times 10^{9} / \mathrm{L}$ OR $14.4 ; \mathrm{p}=0.02$; hypocellular or dry tap aspirate OR 7.0; $\mathrm{p}=0.02$ and high serum alkaline phosphatase OR $6.5 ; \mathrm{p}=0.03$. Three additional factors were found to be associated with deceased survival. Thrombocytopenia was associated with decreased survival from a median of 0.8 months to 4.1 months, $\mathrm{p}<0.0001$. Serum LDH levels more than twice the upper limit of normal were also reduced survival from 1.8 months versus 4.7 months, $\mathrm{p}=0.03$. Finally, the initial diagnosis of malignancy by bone marrow examination was associated with reduced survival from 1.8 months vs. 4.0 months, $\mathrm{p}=0.03$ in individuals where $\mathrm{BM}$ metastases were not the presenting feature of malignancies. Use of these simple clinical parameters may help in the early diagnosis of bone marrow metastases and improve clinical approach.
\end{abstract}

\section{Keywords}

Bone Marrow Metastasis, Predictive Factors, Survival, Solid Tumor

\section{Introduction}

Bone marrow (BM) metastases are diagnosed in $0.2 \%-12 \%$ patients with solid malignancies. Most frequently affected are individuals with neuroblastoma or 
Ewing's sarcoma, as well as those with breast, prostate and small cell lung cancer (SCLC) [1] [2] [3]. Marrow metastases are frequently indicative of metastases to other sites [4] and often predict a rapidly progressive clinical course with shortened survival which could affect the approach to treatment [2] [5]. Unfortunately, BM metastases are frequently detected only on the postmortem examination [6] [7].

The recent introduction of novel diagnostic methods for detection of disseminated tumor cells (DTC) such as reverse-transcriptase polymerase reaction (RT-PCR), fluorescent in situ hybridization (FISH), flow cytometry, and native or cultured bone marrow cells has greatly increased the likely detection of BM metastases [8] [9] [10] [11]. However, these techniques are not yet routinely applied or standardized. Furthermore, the prognostic impact of low-burden BM metastatic spread is still controversial [8] [12] and their effect on the therapeutic approach remains unclear [13].

Radiologic examination using computed tomography with positron emission tomography (PET-CT) or magnetic resonance imaging (MRI) the most commonly utilized noninvasive procedures for the diagnosis of BM metastasis in cancer [14]. However, these assays may not completely replace BM examination especially in cases of suspected BM involvement by malignancies of unknown primary site.

Many laboratory parameters associated with BM metastasis have been discussed in the literature but their diagnostic significance is not clearly defined [15]. These include microangiopathic hemolytic anemia, thrombocytopenia, leukocytosis, elevated red cell distribution (RDW), high serum lactate dehydrogenase (LDH), alkaline phosphatase (ALP) uric acid and leukoerythroblastic blood picture.

Morphologic and immunohistochemical evaluation of the bone marrow by aspirate and biopsy is a readily available and technically simple procedure associated with a low rate of morbidity. It is an effective approach for the diagnosis of metastases in a cancer patient with a defined diagnosis and clinical suspicion for marrow involvement [16]. Moreover, when the primary site of the tumor is unknown, the detection and characterization of malignant cells in the BM may help to elucidate the primary source and prevent additional unnecessary diagnostic procedures [17]. Furthermore, the presence of BM metastases may be helpful in identifying hormonal receptors to help provide accurate treatment in patients whose primary tumor is unknown or inaccessible [18]. Nevertheless, marrow examination is not a routine assay in cancer patients, and the indications and diagnostic significance of these procedures have not been fully clarified.

The aim of this study was to investigate the clinical and laboratory characteristics as well as the outcome of patients with metastatic cancer who underwent bone marrow examination in our institution. We attempted to identify parameters associated with BM metastasis and risk factors which may impact survival in these individuals. We separately analyzed a subgroup of patients who were in- 
itially diagnosed with malignancy by marrow examination to help elucidate the role of this procedure may play in helping to identifying the primary tumor source.

\section{Materials and Methods}

Results of BM biopsies and corresponding aspirates performed in our institution between June 2000 and April 2011 were retrospectively reviewed. A total 3619 BM biopsies were performed during this period of which 86 (2.4\%) revealed non-hematologic tumor cells. Fourteen patients with concomitant hematological malignancy, lacking routine laboratory tests or who were lost to follow up were excluded from further analysis. These 72 individuals were divided into two groups: those patients who were referred for BM biopsy with a prior established diagnosis of metastatic tumor and in whom the biopsy confirmed BM involvement $(\mathrm{n}=34)$, and individuals in whom the initial diagnosis of malignancy was the result of the BM biopsy ( $\mathrm{n}$ $=38$ ). As a control group we selected cases in which a prior malignancy was known but in whom BM biopsy was negative $(\mathrm{n}=31)$. A final total of 103 individuals were included in this study (Figure 1).

Demographic characteristics, clinical data, location of primary tumor and additional metastases, hematological and biochemical test results, results of blood smear test, BM aspirate and trephine biopsy, as well survival time after $\mathrm{BM}$ examination were recorded for each individual. In general, BM aspirate and biopsy samples were obtained using routine technique from at least two different locations in the posterior superior iliac crest and occasionally from the anterior iliac spine. This was done in order to overcome limitation of unilateral examination due to focal metastatic spread (Figure 2).

The average length of the core biopsies was $1.6 \mathrm{~cm}$ (range $1.1 \mathrm{~cm}$ to $2.8 \mathrm{~cm}$ ). Marrow biopsies were fixed in $10 \%$ buffered formalin, decalcified overnight in equal parts $10 \%$ formic acid and $8 \%$ hydrochloric acid, embedded in paraffin blocks, sectioned and initially stained with hematoxylin and eosin. Stain for pancytokeratin was performed routinely while additional immunohistochemical stains

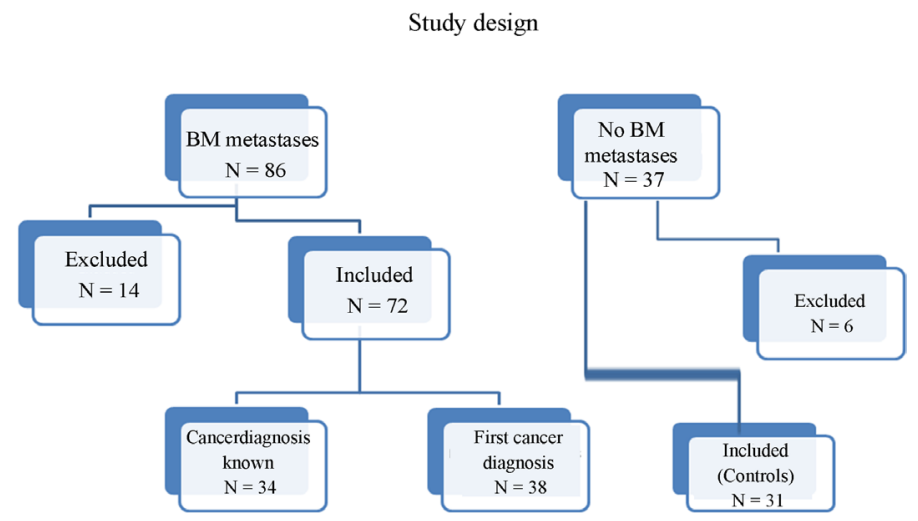

Figure 1. Study design. 


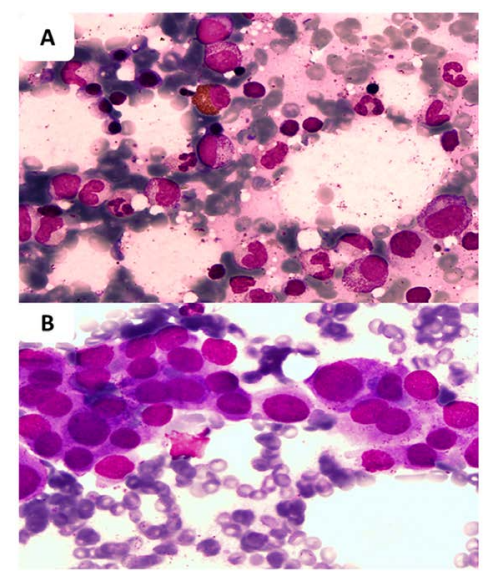

A. Bone marrow aspirate from a 74 year old female with an osteolytic lesion taken from the posterior iliaccrest showing a polymorphic normocellularBM picture. (Wright-Giemsa, original magnification $\mathrm{X} 400$ )

B. Bone marrow smear (magnification X 400 ) and C (original magnification X 1000) performed simultaneously from the anterior superior iliac showing complete replacement of the hematopoietic process by clusters of large atypical cells with oval to round irregular nuclear membranes. A portion of these cells are binucleated with immature chromatin and fine basophiliccytoplasm, with immature chromatin and fine basophiliccy
morphologically suggestive of breast origin

Figure 2. Metastasis.

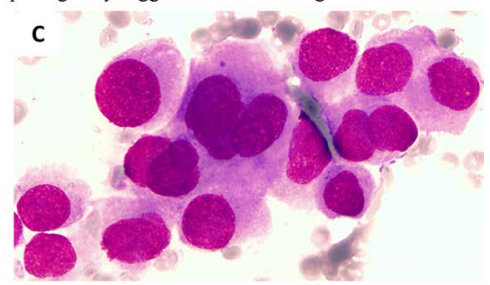

were performed as indicated. Touch imprint from the core biopsy was prepared in 43 out of $103(41.7 \%)$ cases including all individuals with a "dry aspiration tap". Peripheral blood and BM aspiration smears and the touch preparations were stained by Wright-Giemsa stain and at least four smears was examined under 20, 50 and 100 magnification.

This study was conducted in accordance with the Declaration of Helsinki and approved by the local ethnic committee.

\section{Statistical Analysis}

The SPSS 17.0 software package for Windows (SPSS Inc, Chicago, USA) was used for the statistical analysis. Basic demographic data were summarized as mean for continuous variables or $\mathrm{n}(\%)$ for categorical parameters. The impact of different variables on predicting the presence of BM metastasis was evaluated by univariate analysis using Chi-square or Student's test. Difference between Groups 1 and 2 of $\mathrm{p} \leq 0.05$ was considered significant. Significant variables were evaluated by multivariate logistic regression analysis. Overall survival (OS) was calculated according to the Kaplan-Meier analysis. Log-rank test was used to define significant between survival curves. OS was determinate as the period elapsed from the date bone marrow biopsy to the date of death.

\section{Results}

Demographic characteristics of the 72 patients with BM metastases and the 31 control cases without BM metastases are summarized in Table 1 . There were no significant differences in age, male to female ratio or site of primary tumor between these groups. Of the 103 combined cases with metastatic disease, the most common primary sites of malignancy were breast $(n=25)$, lung $(n=23)$, prostate $(\mathrm{n}=21)$ and gastrointestinal tract $(\mathrm{n}=12)$. Cytopenia, predominantly thrombocytopenia, was the most common indication for marrow examination in 44 (61\%) patients with BM metastasis, followed by bone lesions in 17 cases (38\%) lymphadenopathy in 8 patients (11\%), unexplained fever and hypercalcemia in $3(4 \%)$ individuals respectively (some patients had more than one indi- 
cation for biopsy). A significant difference was found in the rate of bone metastases diagnosed by imaging studies , $74 \%$ in the metastatic BM group versus $58 \%$ in controls $(\mathrm{p}=0.008)$.

As summarized in Table 2, thrombocytopenia $\left(<140 \times 10^{9} / \mathrm{L}\right)$ was found in 40

Table 1. Demographic characteristics and primary location of metastatic solid tumors.

\begin{tabular}{|c|c|c|c|}
\hline & \multicolumn{2}{|c|}{ Metastatic tumor patients } & \multirow[b]{2}{*}{$P$ value } \\
\hline & $\begin{array}{l}\text { With BM Metastases } \\
\qquad \mathrm{N}=72\end{array}$ & $\begin{array}{l}\text { Without BM metastases } \\
\qquad \mathrm{N}=31\end{array}$ & \\
\hline Mean age (range) & $67(31-91)$ & $70(34-96)$ & 0.36 \\
\hline Male: female ratio & $1: 1.1$ & $1.8: 1.1$ & 0.13 \\
\hline Carcinoma type & \multicolumn{2}{|c|}{ Number (\%) } & \\
\hline Breast & $21(29)$ & $4(13)$ & ns \\
\hline Prostate & $16(22.5)$ & $5(16)$ & ns \\
\hline GI tract & $7(9.7)$ & $5(16)$ & ns \\
\hline Lung & $(22.5)$ & $(22.5)$ & \\
\hline SCLC & 7 & 3 & ns \\
\hline NSLSC & 9 & 4 & ns \\
\hline Unknown origin & $9(12.5)$ & $4(13)$ & ns \\
\hline Other & 3 & 6 & \\
\hline \multicolumn{4}{|l|}{ Other metastases } \\
\hline Brain & $10(14 \%)$ & $4(13)$ & ns \\
\hline Lung, liver, adrenal & $31(43)$ & $13(42)$ & ns \\
\hline Bone $^{*}$ & $53(74)$ & $18(58)$ & 0.008 \\
\hline
\end{tabular}

*Suspected by imaging: $\mathrm{x}$-ray, CT, MRI or bone scan.

Table 2. Laboratory parameters of 103 patients with metastatic malignancy.

\begin{tabular}{|c|c|c|c|}
\hline $\begin{array}{l}\text { Characteristic } \\
\text { (normal range) }\end{array}$ & $\begin{array}{c}\text { Patient with Bone } \\
\text { marrow metastasis }(n=72)\end{array}$ & $\begin{array}{l}\text { Without Bone marrow } \\
\text { metastasis }(\mathrm{n}=31)\end{array}$ & $P$ value \\
\hline $\mathrm{Hb}$ mean $\mathrm{g} / \mathrm{dL}$ (range) & $10.3(3.5-14.6)$ & $11.2 \pm 1.86$ & 0.023 \\
\hline \multicolumn{4}{|l|}{ Normal range $(12-15 \mathrm{~g} / \mathrm{dL})$} \\
\hline$<12 \mathrm{~g} / \mathrm{dL}$ incidence $\%$ & $83.3 \%$ & $61.3 \%$ & 0.015 \\
\hline $\begin{array}{l}\text { White blood cell, mean }(\text { range })) \\
\text { Normal range }\left(4.5-11 / \times 10^{9}\right)\end{array}$ & $9.3(1.2-89.6)$ & $7.8(1.28-15.9)$ & 0.43 \\
\hline PLT count, mean $\times 10^{9} / \mathrm{L}$ & $159(4-570)$ & $264(27-486)$ & $<0.001$ \\
\hline PLT $<140 \times 10^{9} / \mathrm{L}$, incidence & $55.6 \%$ & $16 \%$ & $<0.001$ \\
\hline PLT $<50 \times 10^{9} / \mathrm{L}$, incidence & $26.4 \%$ & $3.2 \%$ & 0.006 \\
\hline $\mathrm{MCV}$, mean fl (range) & $86.2(66-109)$ & $86.9(80-101)$ & 0.5 \\
\hline RDW, mean (range \%) & $16.6(13-26)$ & $16.0(13-25)$ & 0.2 \\
\hline MPV, mean fl (range) & $8.73(7-12)$ & $8.17(6.3-9.5)$ & 0.03 \\
\hline Albumin, mean g/dL (range) & $3.4(2.3-4.6)$ & $3.2(1.9-4.8)$ & 0.35 \\
\hline Calcium, mean $\mathrm{g} / \mathrm{dL}$ & $8.97(6.8-11.2)$ & $8.9(7.2-10.2)$ & 0.6 \\
\hline $\mathrm{LDH}$, mean U/L & $1515(234-9200)$ & $992(306-6465)$ & 0.12 \\
\hline$>2$ ULN (480 U/L), incidence & $50 \%$ & $16.7 \%$ & 0.002 \\
\hline Alkaline phosphatase, mean U/L & $283(51-1086)$ & $132(46-701)$ & $<0.001$ \\
\hline$>2$ ULN (104 U/L), incidence & $35.7 \%$ & 9.7 & 0.007 \\
\hline Ferritin ng/mL, mean (range) & $1759(220-4480)$ & $254(3.7-650)$ & 0.007 \\
\hline Hypoplastic/dry tap BM aspirate & $58.8 \%$ & 16.6 & 0.001 \\
\hline
\end{tabular}


of 72 patients $(55.6 \%)$ with BM spread compared to 5 of $31(16 \%)$ without this finding $(\mathrm{p}<0.001)$. Furthermore, severe thrombocytopenia $\left(<50 \times 10^{9} / \mathrm{L}\right)$ was noted in 19 patients with BM metastases $(26.4 \%)$ as compared to only one individual in the no metastases group $(3.2 \%$; $\mathrm{p}=0.006)$. Mean platelet volume was also found to be significantly different measuring an average of $8.73 \mathrm{fl}$ in patients with metastatic marrow involvement and $8.17 \mathrm{fl}$ in those without $(\mathrm{p}=0.014)$.

Anemia defined as hemoglobin $<12 \mathrm{~g} / \mathrm{dL}$ was noted significantly more often in patients with metastatic marrow $(n=60,83 \%)$ versus non-affected individuals $(\mathrm{n}=19 ; 61 \%)(\mathrm{p}=0.015)$. Leukoerythroblastic picture in the blood smear was observed in 28 of 34 (82.4\%) patients with BM involvement and in no one without $(\mathrm{p}<0.001)$. Elevation of serum lactate dehydrogenase $(\mathrm{LDH})$ and alkaline phosphatase (ALP) levels more than two times the upper limit of normal (UNL) was seen in a significantly higher percentage of patients with marrow involvement than without: $50 \%$ versus $16 \%$; $=0.002$ for $\mathrm{LDH}$ and $35 \%$ versus $9 \%$; $\mathrm{p}=$ 0.007 for ALP. Finally, mean serum ferritin level was noted to be significantly higher in patients with marrow metastasis than unaffected individuals (1760 $\mathrm{ng} / \mathrm{ml}$ versus $255 \mathrm{ng} / \mathrm{ml} ; \mathrm{p}=0.027)$.

Aside from the direct finding of tumor cells in the aspirate, multivariate analysis revealed three additional factors which were associated with the presence of metastases on BM biopsy: thrombocytopenia $<50 \times 10^{9} / \mathrm{L}$ (OR 14.4; 95\% CI, 1.62 - 129; $\mathrm{p}=0.02$ ); hypocellular/ dry tap aspirate (OR 7.0; 95\% CI, 2 - 23.6; p = 0.02 ) and elevated serum alkaline phosphatase (OR 6.5; 95\% CI, $1.2-35.3 ; \mathrm{p}=$ $0.03)$. In contrast, elevated serum LDH was not found to be significantly correlated with BM spread (OR 1.36; 95\% CI, 0.32 - 5.7; $\mathrm{p}=0.2$ ).

Cytological examination of BM aspirate recognized malignant cells in 46 out of $60(76.6 \%)$ patients. Marrow involvement by aspirate was diagnosed in 13 of 14 patients (93\%) with prostate carcinoma, 13 of 18 (\%) with breast, 9 of 15 (\%) with lung, 3 of 4 with gastrointestinal, and 5 out of 6 patients with malignancy of unknown origin. Hypocellular or dry tap marrow aspirate was found in 35 out of $60(58.8 \%)$ patients with BM involvement and in only 5 out of 30 patients (14\%) without ( $\mathrm{p}=0.001$ ). Of the 38 patients in whom the diagnosis of cancer was initially established by marrow biopsy, 29 (76.3\%) had the primary tumor site established during further clinical investigation. Of interest, pathologic study alone was sufficient to establish the primary tumor in approximately half of these individuals, most commonly prostate (7 of 8 ) and lung (10 of 14) primaries.

We further compared the clinical characteristics of patients who had a prior malignancy diagnosis who were referred for staging or with an unrelated clinical indication for marrow biopsy, with those individuals in whom malignancy was initially diagnosed by the marrow examination. The group with cancer diagnosed by BM biopsy had similar mean age $(\mathrm{p}=0.14)$ but a higher proportion of males $(70 \%, p=0.009)$, more frequently suffered from severe thrombocytopenia and had a higher incidence of small cell lung cancer $(n=9,23.6 \%$ vs. $n=2,6 \%$, $\mathrm{p}=0.03)$.

All 103 patients died, but median survival for patients with marrow involvement was significantly shorter than for those without (2.2 versus 5.1 months; $\mathrm{p}=$ 
0.023). We separately analyzed risk factors associated with patient survival with metastatic BM involvement. For severe thrombocytopenia median survival was reduced to 0.8 months (95\% CI, 0.1 - 1.5) versus 4.1 months for unaffected individuals (95\% CI 2.0 - 6.1); p < 0.0001) (Figure 3). Elevated serum LDH was similarly associated with decreased survival from a mean of 1.8 months (95\% CI; 0.5 - 3.0) versus 4.7 months in those with normal serum levels (95\% CI; 3.0 - 6.3, p = $0.03)$. The initial diagnosis of malignancy by bone marrow examination also was a marker for decreased survival to 1.8 months (95\% CI; 0.3 - 3.3) from a baseline

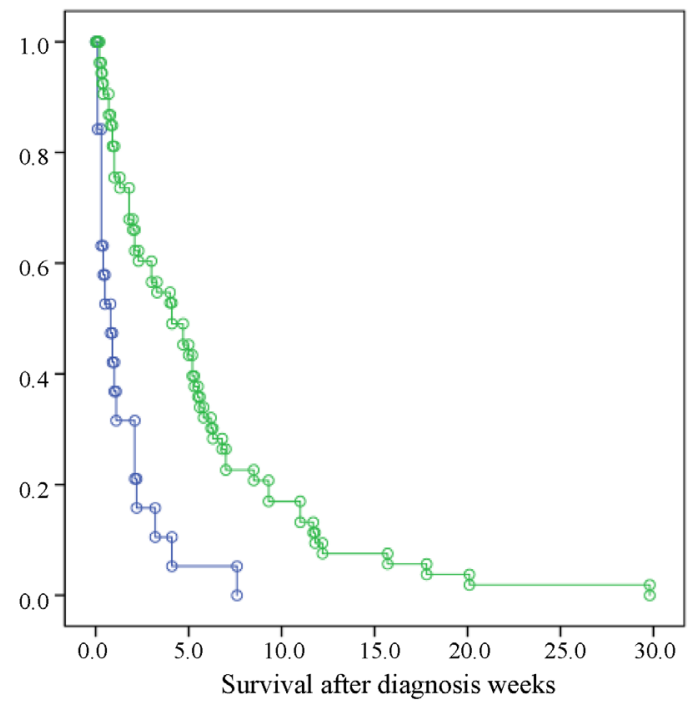

(a)

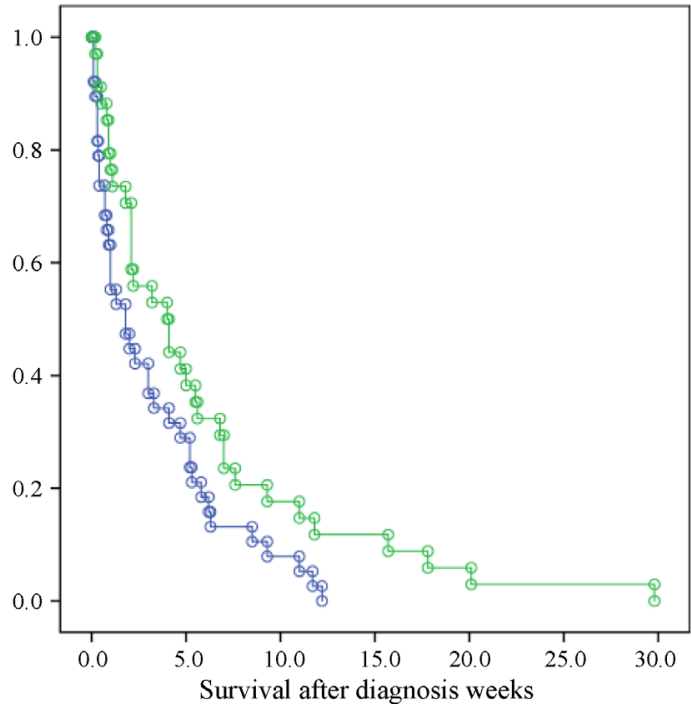

(b)

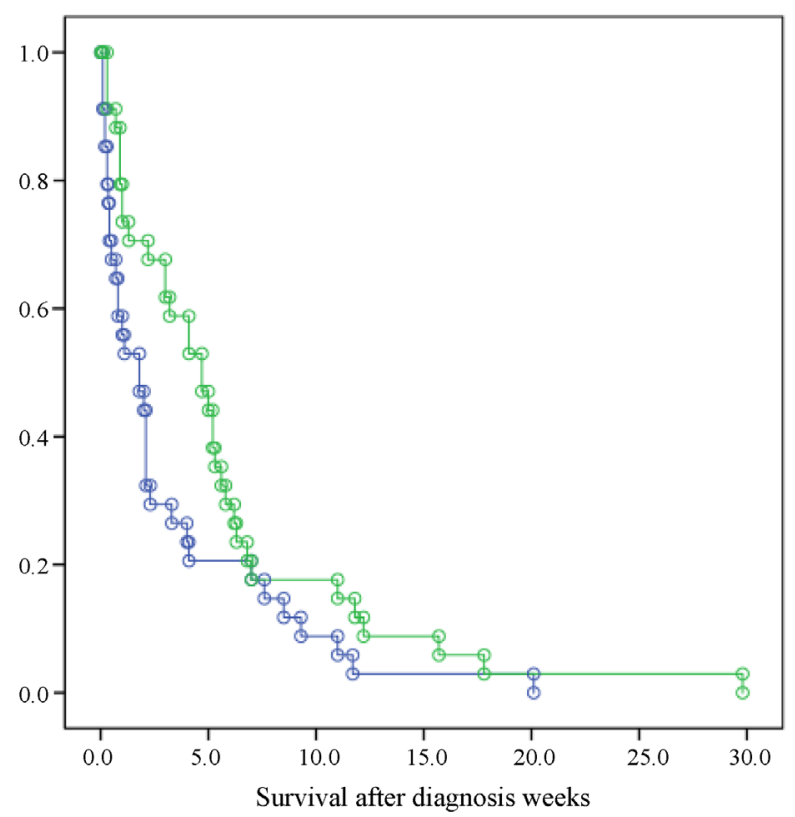

(c)

Figure 3. (a) Median Survival of patients (weeks) after diagnosis BM metastasis with PLT $>50 \mathrm{k} / \mathrm{Ul}$ (green line) 4.1 months versus PLT $<50 \mathrm{k} / \mathrm{uL}$ (blue line) 0.8 months, $\mathrm{p}<0.001$; (b) Median survival of patients with previously known metastatic cancer $4.0 \mathrm{~m}$. vs initially diagnosed with malignancy by BM examination $1.8 \mathrm{~m}, \mathrm{p}=0.03$; (c) Median survival according to LDH level $<2 \mathrm{ULN}$ (upper limit of normal) $4.7 \mathrm{~m}$ vs. $\mathrm{LDH}>2 \mathrm{ULN} 1.8 \mathrm{~m}, \mathrm{p}=0.043$. 
of 4.0 months if the diagnosis was established by other means (95\% CI; 1.3 - 6.7, $\mathrm{p}=0.03)$.

\section{Discussion}

Metastatic BM involvement has a known negative effect on the clinical course of malignancy, and may alter choice of the treatment regimen because of limited hematopoietic reserve and worsened patient outcome. However, detection of BM metastases may be helpful to identify hormonal receptors to help provide accurate treatment in patients whose primary tumor is unknown or inaccessible [18].

In this study we evaluated the efficacy and prognostic significance of BM examination in patients with metastatic cancer, and analyzed the clinical and laboratory characteristics of this patient population. In this 10 year retrospective review we identified 103 individuals with metastatic malignancy in which 72 had marrow infiltration by biopsy. As in other studies a higher incidence was observed in patients affected with breast, lung and prostate cancer. BM metastases occurred not only in patients with known disseminated carcinomas, but also as the presenting clinical manifestation. In over half of our patients the primary localization of their solid tumor was diagnosed by BM examination, a relatively high proportion when compared with other recent publications [19].

As in other published studies [20] [21] BM involvement in our patient cohort was associated with a significant reduction in survival: 2.2 months compared to 5.1 months in those without such metastases $(\mathrm{p}=0.023)$. Particularly short survival of 0.8 months was noted in patients with severe thrombocytopenia $(<50 \times$ $10^{9} / \mathrm{L}$ ) confirming previously published reports [22] [23]. Severely reduced platelet counts are felt to decrease patient tolerance to antitumor therapy and increase the incidence of fatal bleeding complications. High LDH level also predicted a poor outcome for patient with BM metastasis (median survival 1.8 months) probably reflecting a high burden of BM metastasis. Individuals whose primary tumor was only diagnosed by bone biopsy also were found to have shorter survival (1.8 months) most likely caused by the delay in diagnosis and resultant therapy decisions.

Despite the potential significance of this complication on the management of patients with malignancy, BM examination is not included in a list of routine assessments. In clinical practice referral for BM biopsy is usually reserved for those patients who develop a significant hematologic abnormality, mainly cytopenia. However, hematologic manifestations in malignant disease may have many different causes making it a priority to define which parameters are likely to be associated with marrow metastases, expediting diagnosis and preventing unnecessary procedures. Several prior studies have also addressed this issue and attempted to evaluate potential clinical indicators [15] [19] [22] [24] [25] [26] [27].

Multivariate analysis of our patient population identified three factors that were correlated with the presence of bone marrow infiltration: thrombocytope- 
nia $<50 \times 10^{9} / \mathrm{L}$ (OR 14.4), hypoplastic or dry tap aspirate (OR 7.0) and high alkaline phosphatase (OR 6.5). Peripheral blood leukoerythroblastic picture (characterized by nucleated and tear drop red cells and immature myeloid precursors) has been proposed previously as a sensitive indicator of BM involvement, described in $19.8 \%$ to $79 \%$ of patients, appearing most frequently in cases of gastrointestinal, prostate and breast cancer, as well as those associated with medullar fibrosis [20] [28] [29] [30] [31] [32]. In our cohort $82 \%$ of patients were seen with this finding perhaps reflecting a late stage of diagnosis. We also found a strong correlation (91.7\%) between dry tap or hypocellular BM aspiration and leukoerythroblastosis in our series. This finding was not included in the final analysis of predictive factors because of the small number of recorded blood smears. However, we consider a leukoerythroblastic picture an important but late sign to the presence underlying metastatic marrow disease.

In contrast to prior reports showing association of low MPV index and BM involvement [33] [34], many of our patients with metastatic BM had a high MPV.

Also in contrast to other published studies [35] [36] our results demonstrated usefulness of BM aspirate examination for detection of cancer cells ( $72 \%$ cases) with very high rate $(93 \%)$ of diagnosis a potential treatable prostate carcinoma.

\section{Conclusion}

In conclusion, patients with $\mathrm{BM}$ metastases have very poor prognosis, particularly those individuals in which the initial diagnosis of malignancy was established on the bone biopsy. Additional poor prognostic factors in these patients include thrombocytopenia and elevated $\mathrm{LDH}$ which also predict a shortened survival. Hypoplastic BM aspirate, thrombocytopenia and high serum alkaline phosphatase were associated with BM involvement in patients with metastatic malignancy and may be indicators of the need to perform this procedure in previously undiagnosed cases. Based on these findings, we propose that these variables be followed in patients with malignancies, and in the absence of other evident causes (drug, DIC, etc.), a BM examination be performed. Accurate, prompt diagnosis of primary solid tumor via BM biopsy may prevent the need for additional invasive procedures and ultimately help in forming an appropriate treatment approach focused on potential treatable primary carcinoma.

\section{References}

[1] Krishnan, C., George, T.I. and Arber, D.A. (2007) Bone Marrow Metastases: A Survey of Nonhematologic Metastases with Immunohistochemical Study of Metastatic Carcinomas. Applied Immunohistochemistry \& Molecular Morphology, 15, 1-7.

[2] Anner, R.M. and Drewinko, B. (1977) Frequency and Significance of Bone Marrow Involvement by Metastatic Solid Tumors. Cancer, 39, 1337-1344.

https://doi.org/10.1002/1097-0142(197703)39:3<1337::AID-CNCR2820390349>3.0. CO;2-X

[3] Barekman, C.L., Fair, K.P. and Cotelingam, J.D. (1997) Comparative Utility of Di- 
agnostic Bone-Marrow Components: A 10-Year Study. American Journal of Hematology, 56, 37-41.

https://doi.org/10.1002/(SICI)1096-8652(199709)56:1<37::AID-AJH8>3.0.CO;2-3

[4] Diel, I.J., Kaufmann, M., Goemer, R., Costa, S.D., Kaul, S. and Bastert, G. (1992) Detection of Tumor Cells in Bone Marrow of Patients with Primary Breast Cancer: A Prognostic Factor for Distant Metastases. The Journal of Clinical Oncology, 10, 1534-1539. https://doi.org/10.1200/JCO.1992.10.10.1534

[5] Banys, M., Solomayer, E.F., Becker, S., Krawczyk, N., Gardanis, K., Staebler, A. and Neubauer, H. (2009) Disseminated Tumor Cells in Bone Marrow May Affect Prognosis of Patients with Gynecologic Malignancies. International Journal of Gynecological Cancer, 19, 948-952. https://doi.org/10.1111/IGC.0b013e3181a23c4c

[6] Jamshidi, K. and Swain, W.R. (1971) Bone Marrow Biopsy with Unaltered Architecture: A New Biopsy Device. The Journal of Laboratory and Clinical Medicine, 77, 335-342.

[7] Elliot, J.A., Østerlind, K., Hirsch, F.R. and Hansen, H.H. (1987) Metastatic Patterns in Small-Cell Lung Cancer: Correlation of Autopsy Findings with Clinical Parameters in 537 patients'. Clinical Oncology, 5, 246-254. https://doi.org/10.1200/JCO.1987.5.2.246

[8] Zatch, O. and Lutz, D. (2006) Tumor Cell Detection in Peripheral Blood and Bone Marrow. Current Opinion in Oncology, 18, 48-56.

https://doi.org/10.1097/01.cco.0000198973.51615.fa

[9] Drageset, V., Nesland, J.M., Erikstein, B., Skovlund, E., Sommer, H., Anker, G., Wist, E., Lundgren, S., Bergh, J. and Kvalheim, G. (2006) Monitoring of Disseminated Tumor Cells in Bone Marrow in High-Risk Breast Cancer Patients Treated with High-Dose Chemotheraphy. International Journal of Cancer, 118, 2877-2881. https://doi.org/10.1002/ijc.21709

[10] Lin, H., Balic, M., Zheng, S., Datar, R. and Cote, R.J. (2011) Disseminated and Circulating Tumor Cells: Role in Effective Cancer Management. Critical Reviews in Oncology/Hematology, 77, 1-11.

[11] Janni, W., Rack, B., Kasprowicz, N., Scholz, C. and Hepp, P. (2012) DTCs in Breast Cancer: Clinical Research and Practice. Recent Results in Cancer Research, 195, 173-178. https://doi.org/10.1007/978-3-642-28160-0_15

[12] Cotta ,C.V., Konoplev, S., Medeiros, L.J. and Bueso-Ramos, C.E. ( 2006) Metastatic Tumors in Bone Marrow: Histopathology and Advances in the Biology of the Tumor Cells and Bone Marrow Environment. Annals of Diagnostic Pathology, 10, 169-192. https://doi.org/10.1016/j.anndiagpath.2006.04.001

[13] Mansi, J.L., Berger, U., McDonnell, T., Pople, A., Raytz, Z., Gazet, J.C. and Coombes, R.C. (1989) The Fate of Bone Marrow Micrometastases in Patients with Primary Breast Cancer. Journal of Clinical Oncology, 7, 445-449. https://doi.org/10.1200/JCO.1989.7.4.445

[14] Fischer, B.M., Mortensen, J., Langer, S.W., Loft, A., Berthelsen, A.K., Petersen, B.I., Daugaard, G., Lassen, U. and Hansen, H.H. (2007) A Prospective Study of PET/CT in Initial Staging of Small-Cell Lung Cancer: Comparison with CT, Bone Scintigraphy and Bone Marrow Analysis. Annals of Oncology, 18, 338-345. https://doi.org/10.1093/annonc/mdl374

[15] Chernow, B. and Wallner, S.F. (1978) Variables Predictive of Bone Marrow Metastasis. Cancer, 42, 2373-2378.

https://doi.org/10.1002/1097-0142(197811)42:5<2373::AID-CNCR2820420538>3.0.CO;2-P

[16] Papac, R.J. (1994) Bone Marrow Metastases: A Review. Cancer, 74, 2403-2413. 
https://doi.org/10.1002/1097-0142(19941101)74:9<2403::AID-CNCR2820740904>3.0.CO;2-F

[17] Wong, K.F., Chan, J.K. and Ma, S.K. (1993) Solid Tumour with Initial Presentation in the Bone Marrow-A Clinicopathologic Study of 25 Adult Cases. Journal of Hematology \& Oncology, 11, 35-42. https://doi.org/10.1002/hon.2900110105

[18] Berger, U., Mansi, J.L., Wilson, P. and Coombes, R.C. (1988) Detection of Estrogen Receptor in Bone Marrow from Patients with Metastatic Breast Cancer. Journal of Clinical Oncology, 5, 1779-1782. https://doi.org/10.1200/JCO.1987.5.11.1779

[19] Li, X., Song, L.X., Tao, Y., Liu, Y.Z., Wu, L.Y. and Quan, P. (2009) Diagnosis of Unknown Nonhematological Tumors by Bone Marrow Biopsy: A Retrospective Analysis of 10,112 Samples. Journal of Cancer Research \& Clinical Oncology, 135, 687-693. https://doi.org/10.1007/s00432-008-0503-2

[20] Demir, L., Akyol, M., Bener, S., Payzin, K.B., Erten, C., Somali, I., Can, A., Dirican, A., Bayoglu, V., Kucukzeybek, Y., Alacacioglu, A., Calli, A.O. and Tarhan, M.O. (2014) Prognostic Evaluation of Breast Cancer Patients with Evident Bone Marrow Metastasis. Breast Journal, 20, 279-287. https://doi.org/10.1111/tbj.12264

[21] Chou, W.C., Yeh, K.Y., Peng, M.T., Chen, J.S., Wang, H.M., Lin, Y.C., Liu, C.T., Chang, P.H., Wang, C.H., Chen, P.T., Hung, Y.S., Lu, C.H. and Li, S.H. (2015) Development and Validation of a Prognostic Score to Predict Survival in Adult Patients with Solid Tumors and Bone Marrow Metastases. Medicine, 23, Article ID: e966.

[22] Kiliçkap, S., Erman, M., Dinçer, M., Aksoy, S., Harputluoglu, H. and Yalçin, S. (2007) Bone Marrow Metastasis of Solid Tumors: Clinicopathological Evaluation of 73 Cases. Turkish Journal of Cancer, 37, 85-88.

[23] Hung, Y.S., Chou, W.C., Chen, T.D., Chen, T.C., Wang, P.N., Chang, H., Hsu, H.C., Shen, W.C., Cheng, W.H. and Chen, J.S. (2014) Prognostic Factors in Adult Patients with Solid Cancers and Bone Marrow Metastases. Asian Pacific Journal of Cancer Prevention, 15, 61-67. https://doi.org/10.7314/APJCP.2014.15.1.61

[24] Ozkalemkas, F., Ali, R., Ozkocaman, V., Ozcelik, T., Ozan, U., Ozturk, H., Kurt, E., Evrensel, T., Yerci, O. and Tunali, A. (2005) The Bone Marrow Aspirate and Biopsy in the Diagnosis of Unsuspected Nonhematologic Malignancy: A Clinical Study of 19 Cases. BMC Cancer, 5, 144. https://doi.org/10.1186/1471-2407-5-144

[25] Sar, R., Aydogdu, I., Ozen, S., Sevinc, A. and Buyukberber, S. (2001) Metastatic Bone Marrow Tumors: A Report of Six Cases and Review of the Literature. Haematologia, 31, 215-223. https://doi.org/10.1163/15685590152763755

[26] Tritz, D.B., Doll, D.C., Ringenberg, Q.S., Anderson, S., Madsen, R., Perry, M.C. and Yarbro, J.W. (1989) Bone Marrow Involvement in Small Cell Lung Cancer. Clinical Significance and Correlation with Routine Laboratory Variables. Cancer, 63, 763766.

https://doi.org/10.1002/1097-0142(19890215)63:4<763::AID-CNCR2820630426>3.0.CO;2-F

[27] Chandra, S., Chandra, H. and Saini, S. (2010) Bone Marrow Metastasis by Solid Tumors-Probable Hematological Indicators and Comparison of Bone Marrow Aspirate, Touch Imprint and Trephine Biopsy. Hematology, 15, 368-372. https://doi.org/10.1179/102453310X12647083621001

[28] Navone, R. and Colombano, M.T. (1984) Histopathological Trephine Biopsy Findings in Cases of 'Dry Tap' Bone Marrow Aspirations. Appl Pathol, 5, 264-271.

[29] D’Angelo, G. and Hotz A.M. (2011) Myelophthisis in Breast Cancer. American Journal of Hematology, 86, 70-71. https://doi.org/10.1002/ajh.21927

[30] 30 Reid, M. (1991) Dry Tap Marrow Aspiration. American Journal of Hematology, 37, 218-219. https://doi.org/10.1002/ajh.2830370322 
[31] Makoni, S.N. and Laber, D.A. ( 2004 ) Clinical Spectrum of Myelophthisis in Cancer Patients. American Journal of Hematology, 76, 92-93. https://doi.org/10.1002/ajh.20046

[32] Delsol, G., Guiu-Godfrin, B., Guiu, M., Pris, J., Corberand, J. and Fabre, J. (1979) Leukoerythroblastosis and Cancer Frequency, Prognosis, and Physiopathologic Significance. Cancer, 3, 1009-1013. https://doi.org/10.1002/1097-0142(197909)44:3<1009::AID-CNCR2820440331>3.0.CO;2-J

[33] Aksoy, S., Kilickap, S., Hayran, M., Harputluoglu, H., Koca, E., Dede, D.S., Erman, M. and Turker, A. (2008) Platelet Size Has Diagnostic Predictive Value for Bone Marrow Metastasis in Patients with Solid Tumors. International Journal of Laboratory Hematology, 30, 214-219. https://doi.org/10.1111/j.1751-553X.2007.00947.x

[34] Yun, H.K., Shin, M.G., Bo, D., Kim, D.W., Cho, D., Shin, J.H., Such, S.P. and Ryank, D.W. (2007) Laboratory Evaluation of Bone Marrow Metastasis: Single Institute Study. Korean Journal of Laboratory Medicine, 27, 96-101. https://doi.org/10.3343/kjlm.2007.27.2.96

[35] Brown, R.S., Dogan, A., Ell, P.J., Payne, H.A., Masters, J.R. and Harland, S.J. (2002) The Comparative Values of Bone Marrow Aspirate and Trephine Obtaining Bone Scan-Targeted Metastases from Hormone-Refractory Prostate Cancer. Prostate Cancer and Prostatic Diseases, 5, 144-151. https://doi.org/10.1038/sj.pcan.4500581

[36] Moid, F. and Palma, L. (2005) Comparison of Relative Value of Bone Marrow Aspirate and Bone Marrow Trephine Biopsies in the Diagnosis of Solid Tumor Metastasis and Hodgkin Lymphoma. Archives of Pathology Laboratory Medicine, 129, 497-550.

Submit or recommend next manuscript to SCIRP and we will provide best service for you:

Accepting pre-submission inquiries through Email, Facebook, LinkedIn, Twitter, etc. A wide selection of journals (inclusive of 9 subjects, more than 200 journals)

Providing 24-hour high-quality service

User-friendly online submission system

Fair and swift peer-review system

Efficient typesetting and proofreading procedure

Display of the result of downloads and visits, as well as the number of cited articles

Maximum dissemination of your research work

Submit your manuscript at: http://papersubmission.scirp.org/

Or contact jct@scirp.org 